\title{
PENCEGAHAN CEDERA DALAM SEPAK BOLA
}

\author{
Oleh: Fathan Nurcahyo \\ Dosen Jurusan Pendidikan Olahraga FIK-UNY
}

\section{Abstrak}

Pada saat berolahraga (terutama olahraga bodycontac langsung) sangat rentan terhadap terjadinya cedera baik otot, tulang, ligamentum maupun persendian yang bisa terjadi pada bagian kepala, bagian badan, bagian lengan tangan, atau bagian tungkai kaki. Olahraga permainan sepak bola merupakan olahraga bodycontac langsung sehingga atlet atau pemain sepakbola akan sangat dekat dengan cedera-cedera pada bagian tersebut. Cedera yang dialami oleh seorang pemain atau atlet sepak bola dapat menyebabkan mundurnya prestasi seorang atlet, trauma, gangguan psikologis, fisik menurun, dan bahkan cacat permanen atau bahkan sampai pada kematian.

Cedera yang terjadi pada olahraga permainan sepak bola antara lain disebabkan oleh beberapa hal, antara lain: kondisi alam atau lingkungan yang kurang kondusif, bodycontac antar pemain atau dengan objek lain, taktik atau teknik dasar yang salah, salah jatuh, beban latihan yang berlebihan (overload), kelelahan (overtraining), kurang pemanasan-penguluran-pendinginan, atau penggunaan perlengkapan olahraga (equipment) yang salah. Cedera yang terjadi dalam cabang olahraga permainan sepak bola ini dapat terjadi pada beberapa bagian, antara lain: (1) cedera pada bagian kepala, misalnya: gagar otak ringan/berat, mimisan pada hidung, pendarahan pada rongga mulut, (2) cedera pada bagian badan, misalnya: pada leher, pada punggung, pada dada atau bahu, (3) cedera pada bagian lengan tangan, misalnya: pergelangan tangan, jari-jari tangan siku, dan (4) cedera pada bagian tungkai-kaki, misalnya: tungkai atas, lutut, ankle, jari-jari kaki, dan telapak kaki.

Pencegahan cedera saat berlatih maupun pada saat bertanding dalam olahraga permainan sepak bola dapat dilakukan oleh seorang pemain atau atlet sepak bola dengan berbagai cara. Cara-cara pencegahan untuk meminimalisasi terjadinya cedera dalam olahraga permainan sepak bola antara lain dengan cara: penerapan pengetahuan, sikap, dan perilaku yang baik dan benar. Pengetahuan, sikap, dan perilaku untuk dapat mencegah terjadinya cedera tersebut dapat diwujudkan dengan cara pencegahan melalui: (1) lingkungan, (2) perlengkapan yang dipakai, (3) latihan, (4) pemanasan, penguluran dan pendinginan yang baik, (4) ketrampilan, (5) pemilihan dan pola makan yang baik, (6) pelatih atau maseur, dan (7) alat bantu atau pertolongan.

Kata Kunci: pencegahan, cedera, sepak bola 
Dewasa ini perkembangan olahraga permainan khusususnya sepak bola sangat cepat dan pesat, sehingga begitu populer dan mendunia di berbagai lapisan masyarakat di berbagai pelosok daerah. Dalam perkembangannya, melihat prospek ke depan yang cukup cerah yang dapat diambil dari dunia olahraga khususnya sepak bola di masa yang akan datang, banyak klub yang berinisiatif membuka sekolah sepak bola (SSB) mulai tingkat usia dâsar atau usia dini, usia remaja, dan usia pascaremaja atau dewasa. Dari yang hanya bertujuan untuk meningkatkan kesehatan atau kebugaran jasmani, pengisi waktu luang/rekreasi, regenerasi pemain, pengembangan prestasi sampai yang bertujuan untuk mendapatkan profit atau keuntungan.

Pada kenyataanya saat ini dalam dunia olahraga khususnya di Indonesia banyak klub belum dapat mengelola aset-aset yang dimilikinya dengan baik antara lain disebabkan oleh beberapa hal, misalnya: (1) tidak ada atau terbatasnya jumlah orang atau tenaga pengelola (pelatih, manajer atau maseur) yang berpengalaman dalam mengembangkan dan meningkatkan prestasi atau bisnis dalam dunia olahraga khususnya sepak bola, (2) tidak ada atau terbatasnya jumlah dan sumber modal atau keuangan untuk pengembangan dan kemajuan dunia olahraga khususnya sepak bola, (3) tidak ada atau terbatasnya jumlah alat dan sarana prasarana yang akan dikelola dan berkualitas untuk dikembangkan demi kemajuan dalam dunia olahraga khususnya sepak bola, (4) adanya gambaran tentang masa depan yang kurang menyenangkan bagi pemain/atlet, setelah pensiun atau tidak menjadi atlet lagi sudah tidak dihargai oleh klub, orang lain, organisasi atau negara, (5) tidak ada atau terbatasnya perhatian dan pembinaan dari pemerintah atau masyarakat terhadap penyelenggaraan kejuaraan atau turnamen olahraga bagi kelompok umur (khususnya usia dini) dalam sepak bola, dan (6) adanya orang tua yang terlalu mengekang aktivitas anaknya (overprotective) karena olahraga sepak bola adalah olahraga bodycontac yang keras dan berbahaya, sehingga rentan terhadap terjadinya cedera.

Permainan sepak bola merupakan permainan bodycontac langsung dan keras yang menuntut kemampuan setiap individu maupun kerja sama tim untuk bergerak, berpikir dan memutuskan segala sesuatu secara cepat dan tepat. Tidaklah mengherankan apabila dalam olahraga sepak bola seorang pemain sangat rentan terhadap terjadinya cedera. Cedera merupakan momok yang paling ditakuti oleh para atlet/pemain, pelatih atau bahkan bagi para suporter tim sepak bola kesayangannya. Dalam perhelatan akhbar sepak bola empat tahunan sekali, yaitu Piala Dunia (FIFA WORLD CUP) tahun 2010 di Afrika Selatan ini ada beberapa negara yang tidak bisa diperkuat oleh pemain bintangnya yang merupakan skuad inti dari tim tersebut dikarenakan pemain yang bersangkutan sedang mengalami cedera yang cukup serius. Menurut Saparjo P (2010), cedera yang cukup serius dialami oleh beberapa pemain bintang, seperti: David Beckham (Inggris, gelandang: cedera otot Hamstring), Rio Ferdinand (Inggris, libero: cedera ligamen lutut), Luis Nani (Portugal, gelandang: cedera bahu), Michael Ballack Jerman, gelandang: cedera pergelangan kaki/ankle), Michael Essien (Ghana, gelandang: cedera lutut), John Obie Mikel (Nigeria, gelandang: cedera lutut), cedera yang dialami tersebut menyebabkan

MEDIIKORA Vol. VI, No. 1, April 2010: 65 - 76 
pemain-pemain tersebut gagal tampil dan beraksi di Piala Dunia tahun 2010 di Afrika Selatan yang merupakan impian setiap pemain sepak bola profesional. Meskipun demikian ada beberapa pemain yang beruntung karena hanya mengalami cedera ringan dan diperkirakan bisa sembuh pada pertengahan babak penyisihan dan tetap bisa tampil di Piala Dunia 2010 di Afrika Selatan. Pemain-pemain tersebut antara lain: Didier Drogba (Pantai Gading, penyerang: cedera siku tangan), Andrea Pirlo (Italia, gelandang: cedera pergelangan kaki/ ankle), Arjen Robben (Belanda, gelandang: cedera otot Hamstring), (Saparjo P, 2010).

Terjadinya cedera yang dialami oleh para pemain atau atlet akan berdampak kurang baik seperti: gangguan prestasi, fisik, atau psikisnya. Di dalam olahraga sepak bola cedera dapat terjadi pada saat latihan atau pertandingan yang disebabkan oleh beberapa hal, misalnya: (1) faktor alam, misalnya cuaca atau lapangan yang tidak rata, (2) pembebanan latihan yang berlebihan (overload), (3) kesalahan pemilihan sepatu/perlengkapan sepak bola, (4) teknik atau taktik yang dilakukan salah, (5) bodycontac, sleeding-tacle dan teknik jatuhan yang salah, (6) kurangnya pemanasan (warning-up), penguluran (streaching) atau pendinginan (colling-down) yang sesuai dengan olahraga yang dilakukan, (7) ketidakmampuan persendian terhadap gerakan yang dilakukan, atau (8) ketidakmampuan persendian di dalam menahan berat badan. Cedera yang dialami oleh seorang pemain atau atlet dapat membuat prestasi seorang atlet menjadi mundur, trauma, gangguan psikologis, fisik menurun, dan bahkan cacat permanen atau bahkan sampai kematian (kasus Liga Indonesia: Jumadi Abdi, gelandang: meninggal akibat benturan keras dan berdasarkan visume dokter terjadi kerusakan/robekan pada organ dalam (usus)). Sebenarnya cedera dapat dicegah atau diminimalisir melalui pengetahuan-lingkungan, pemilihan perlengkapan olahraga, latihan, pemanasan-penguluran-pendinginan yang baik dan benar, keterampilan dan mengatur menu serta pola makan. Apabila telah terjadi cedera hanya tinggal dua cara, yaitu perawatan (penggunaan alat bantu, terapi/pijat) dan dengan jalan operasi (medis).

Inti dari permasalahan yang akan menjadi pokok pembahasan dalam penulisan karya tulis ini, antara lain:

1. Cedera apa saja yang lazim dan mungkin terjadi dalam olahraga permainan sepak bola?

2. Faktor-faktor apa saja yang menjadi penyebab terjadinya cedera dalam olahraga permainan sepak bola?

3. Bagaimana pencegahan dan perawatan cedera yang baik yang timbul dalam olahraga permainan sepak bola?

\section{KAJIAN PUSTAKA}

\section{Permainan Sepak Bola}

Sepak bola merupakan permainan modern yang sangat memasyarakat dan mendunia di berbagai kalangan masyarakat, dan tidaklah mengherankan apabila olahraga ini sekarang dapat dimainkan oleh anak-anak maupun dewasa ataupun oleh kaum wanita. Menurut Sukintaka (1982: 70) permainan sepak bola adalah 
permainan bola besar yang dimanipulasi dengan kaki dan seluruh anggota badan kecuali tangan yang dimainkan oleh dua buah regu yang masing-masing regu terdiri atas sebelas orang pemain. Permainan sepak bola biasanya dimainkan dalam dua babak dan diberi waktu istirahat di antara kedua babak itu. Tiap-tiap regu berusaha memasukkan bola sebanyak-banyaknya ke gawang lawan dan mempertahankan gawangnya sendiri agar jangan sampai kemasukan. Regu yang lebih banyak mencetak gol dinyatakan sebagai pemenang dalam pertandingan. Agar permainan itu dapat berdaya guna dan berhasil guna diperlukan kerja sama dan tolong menolong dalam satu regu dan setiap pemain dalam satu regu diberi kewajibankewajiban sendiri yang dibagi dalam tiga kelompok besar, yaitu: barisan penyerang, barisan penghubung, dan barisan bertahan.

Menurut pendapat yang lain seperti yang dikemukakan oleh Wade (1978: 3), sepak bola adalah:

.... a game played between two team. When one time has the ball they try to score by dribbling it, running with it, kicking it, heading it, and passing it with from one player to the other so that finally the ball is played through, past or over opposing players to score a goal. The team which does not have the ball tries to prevent shots towards the goal which it is defending by tackling for the ball, blocking shots, marking dangerous opponents, and by kicking, beading, dribbling, or passing the ball away from danger areas near to goal. At the highest level, the game is played by eleven players in a team.

Menurut pendapat Hurlock (1990), yang dikutip oleh M. Furqon H (2002: 5-6), permainan sepak bola sebaiknya mulai dikenalkan pada anak usia dini pada saat berusia antara 10-12 tahun dan masuk pada tahap spesialisasi pada saat berumur 11-13 tahun dan diharapkan dapat mencapai puncak prestasinya pada saat berumur 18-24 tahun.

Tabel 1. Data Tabel Usia Dini Berolahraga, Usia Spesialisasi, dan Usia Pencapaian Prestasi Puncak

\begin{tabular}{|c|l|c|c|c|}
\hline No. & \multicolumn{1}{|c|}{$\begin{array}{c}\text { Cabang } \\
\text { Olahraga }\end{array}$} & $\begin{array}{c}\text { Usia Dini } \\
\text { Berolah Raga } \\
\text { (Thn) }\end{array}$ & $\begin{array}{c}\text { Usia } \\
\text { Spesialisasi } \\
\text { (Thn) }\end{array}$ & $\begin{array}{c}\text { Usia Pencapaian } \\
\text { Prestasi Puncak } \\
\text { (Thn) }\end{array}$ \\
\hline 1 & Atletik & $10-12$ & $13-14$ & $18-23$ \\
\hline 2 & Basket & $8-9$ & $10-12$ & $20-25$ \\
\hline 3 & Tinju & $13-14$ & $15-16$ & $20-25$ \\
\hline 4 & Renang & $3-7$ & $10-12$ & $16-18$ \\
\hline 5 & Senam & $6-7$ & $10-11$ & $14-18$ \\
\hline 6 & Bolavoli & $11-12$ & $14-15$ & $20-25$ \\
\hline 7 & Sepakbola & $\mathbf{1 0 - 1 2}$ & $\mathbf{1 1 - 1 3}$ & $\mathbf{1 8 - 2 4}$ \\
\hline 8 & Tenis & $6-8$ & $12-14$ & $22-25$ \\
\hline 9 & Dst & - & - & - \\
\hline
\end{tabular}

Sumber: Pembinaan Olahraga Usia Dini (M. Furqon H., 2002: 6)

MEDIKORA Vol. VI, No. 1, April 2010: 65 - 76 
Berdasarkan teori piramida dari M. Furqon (2002: 5) terdapat tiga tahapan yang ideal di dalam melakukan pembinaan olahraga prestasi, yaitu: (1) pemassalan olahraga, (2) pembibitan atlet, dan (3) pembinaan prestasi puncak.

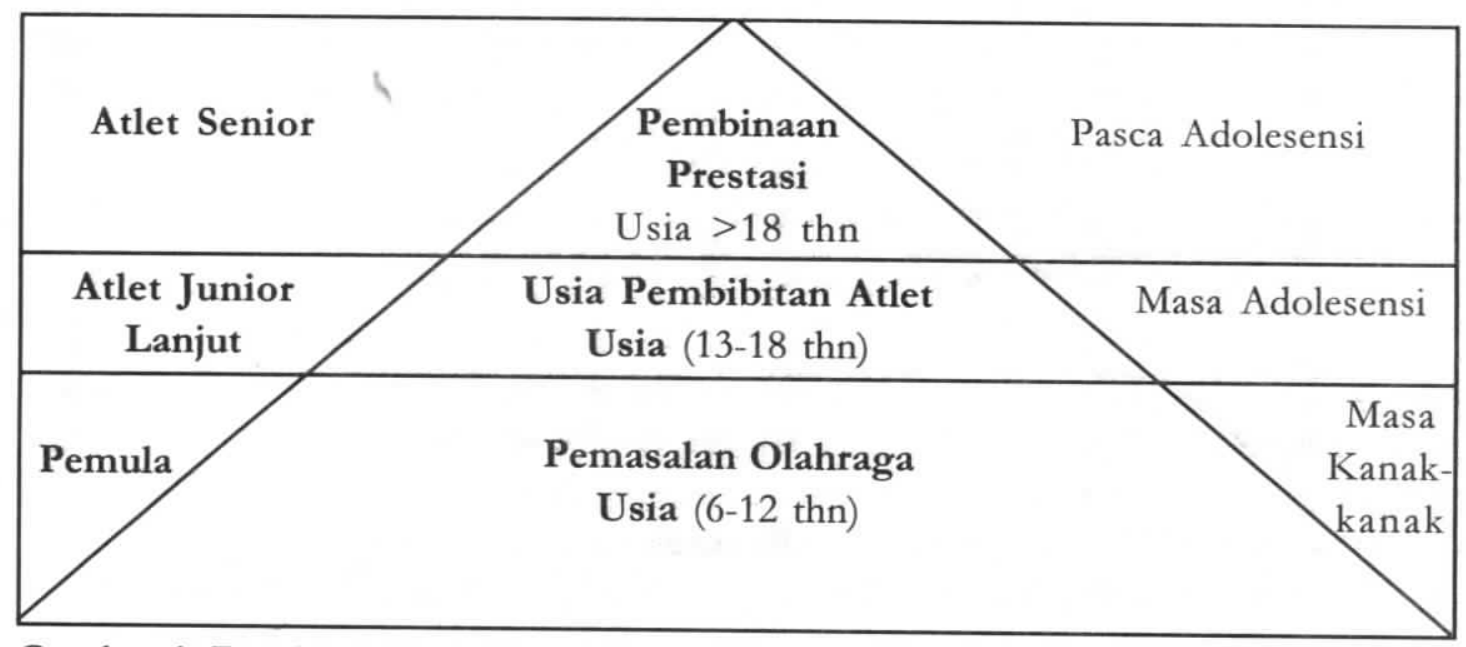

Gambar 1. Pembinaan Olahraga Usia Dini ditinjau dari Teori Piramida Emas (M. Furqon H., 2002: 5)

\section{Pengertian Cedera dalam Dunia Olahraga}

Cedera dalam dunia olahraga merupakan sesuatu yang sangat ditakuti baik oleh pemain (atlet), pelatih (coach), manajer, maupun oleh suporter. Menurut Syamsuri E (1984: 36) cedera adalah memar atau luka, atau dislokasi dari otot, sendi atau tulang yang disebabkan oleh kecelakaan, benturan (bodycontac) atau gerakan yang berlebihan, sehingga otot, tulang, atau sendi tidak dapat menahan beban atau menjalankan tugasnya. Cedera dalam dunia olahraga yaitu rusaknya jaringan (lunak atau keras) baik otot, tulang, atau persendian yang disebabkan oleh kesalahan teknis, benturan, atau aktivitas yang melebihi batas beban latihan (overtraining) yang dapat menimbulkan rasa sakit atau nyeri dan atau akibat dari kelebihan latihan dalam memberikan pembebanan yang terlalu berat (overload), sehingga otot, tulang, atau persendian tidak lagi dalam keadaan atau posisi anatomis (dislokasi), (G. La. Cava, 1995: 145). Menurut Hadianto W (1995: 11) cedera dalam olahraga adalah segala macam cedera yang timbul pada waktu latihan ataupun pada waktu pertandingan.

Menurut pendapat yang dikemukakan oleh Hadiyanto W (1995: 15) cedera dalam dunia olahraga dapat dikategorikan menjadi tiga tingkatan, yaitu: cedera ringan/ cedera tingkat pertama, cedera sedang/cedera tingkat kedua, dan cedera berat/cedera tingkat ketiga.

a. Cedera Ringan/Cedera Tingkat Pertama

Cedera ringan/cedera tingkat pertama ini ditandai dengan adanya robekan atau hanya dapat dilihat dengan mikroskop, dengan keluhan minimal, dan 
hanya sedikit saja atau tidak terlalu mengganggu penampilan atlet yang bersangkutan baik pada saat berlatih ataupun bertanding.

b. Cedera Sedang/Cedera Tingkat Kedua

Cedera sedang/cedera tingkat kedua ini ditandai dengan kerusakan jaringan yang nyata, nyeri, bengkak, memar, berwarna kemerah-merahan (suhu agak panas), dengan gangguan fungsi yang nyata dan berpengaruh pada penampilan atlet yang bersangkutan baik pada saat berlatih maupun bertanding.

c. Cedera Berat/Cedera Tingkat Ketiga

Cedera berat/cedera tingkat ketiga ini ditandai dengan kerusakan jaringan atau terjadi robekan lengkap atau hampir lengkap pada otot, ligamentum, dan fraktur pada tulang yang memerlukan waktu istirahat lebih lama atau total, dan membutuhkan terapi, pengobatan secara intensif, dan bahkan dimungkinkan untuk dioprasi.

\section{Macam-Macam Cedera dalam Olahraga}

Secara umum menurut pendapat yang dikemukakan oleh Paul dan Diare (1993: 63), cedera yang mungkin dapat terjadi pada saat latihan atau pertandingan olahraga, antara lain: cedera memar, cedera ligamentum, cedera pada otot atau tendo, pendarahan pada kulit, dan pingsan.

a. Cedera Memar

Memar adalah cedera yang disebabkan oleh benturan (bodycontac) atau pukulan langsung pada permukaan kulit. Akibat dari benturan atau pukulan tersebut dapat menyebabkan jaringan di bawah kulit akan rusak dan pembuluh darah kecil akan robek atau pecah sehingga darah dan cairan seluler akan keluar atau merembes ke jaringan di sekitarnya.

b. Cedera pada Otot atau Tendo dan Cedera Ligamentum

Menurut pendapat yang dikemukakan oleh Hadianto W (1993: 13), ada dua jenis cedera yang dapat terjadi pada otot atau tendo dan ligamentum, yaitu strain dan sprain. Menurut pendapat yang dikemukakan oleh Giam dan Teh (1993: $92-$ 93), strain adalah kerusakan pada suatu bagian jaringan otot atau tendo karena penggunaan yang berlebihan ataupun stress yang berlebihan. Sprain adalah cedera pada bagian persendian dengan diikuti terjadi robekan pada ligamentum, hal ini disebabkan oleh stress berlebihan yang mendadak atau penggunaan yang berlebihan secara berulang-ulang dari persendian.

Permainan sepak bola merupakan permainan bodycontac yang memiliki kekompleksivitasan yang tinggi dalam mempergunakan berbagai jenis gerakan sehingga akan sangat rentan terhadap terjadinya cedera baik pada saat latihan maupun pada saat pertandingan. Dalam permainan sepak bola, cedera strain dan sprain antara lain dapat terjadi pada:

MEDIIKRAA Vol. VI, No. 1, April 2010: 65 - 76 


\section{1) Pergelangan Kaki (ankle)}

Cedera ini dapat terjadi misalnya karena terkilir pada saat menggiring bola atau berlari zig-zag, bodycontac/ sleeding-tacle, lapangan yang tidak rata, kesalahan pada saat melakukan gerakan teknik dasar, atau penggunaan jenis sepatu yang tidak sesuai.

2) Jari-Jari Kaki

Cedera ini dapat terjadi karena adanya bodycontac (terinjak), lapangan tidak rata, kesalahan pada saat melakukan gerakan teknik dasar, penggunaan jenis sepatu yang tidak sesuai atau gesekan antara kulit dan sepatu (melepuh).

3) Lutut (Knee Injuries)

Cedera ini dapat terjadi karena terkilir pada saat menggiring bola atau berlari zig-zag/putar badan yang melebihi kemampuan sendi lutut, bodycontac/sleeding-tacle, benturan antar kaki, ketidakmampuan sendi lutut atau ligamentum dalam melakukan gerakan atau menahan beban berat badan, lapangan yang tidak rata, kesalahan melakukan gerakan teknik dasar atau penggunaan jenis sepatu yang tidak sesuai.

4) Bahu

Cedera ini dapat terjadi, misalnya disebabkan oleh terjadinya bodycontac/ sleeding-tacle antar pemain atau jatuhnya badan pada tanah tidak benar.

5) Tulang Belakang/Punggung (Vertebrae)

Cedera ini dapat terjadi, misalnya disebabkan oleh terjadinya bodycontac/ sleeding-tacle antar pemain, jatuhnya badan pada tanah tidak benar, ketidakseimbangan otot dan peregangan ligamen tulang belakang yang berlebihan.

6) Pergelangan Tangan

Cedera ini dapat terjadi, misalnya disebabkan oleh terjadinya bodycontac/ sleeding-tacle antar pemain atau jatuhnya badan pada tanah tidak benar (tangan menopang/menahan beban berat badan yang berlebihan).

7) Siku (Elbow)

Cedera ini dapat terjadi, misalnya disebabkan oleh terjadinya bodycontac/ sleeding-tacle antar pemain atau jatuhnya badan pada tanah tidak benar (tangan menopang/menahan beban berat badan yang berlebihan).

8) Jari-jari Tangan

Cedera ini dapat terjadi, misalnya disebabkan oleh terjadinya bodycontac/ sleeding-tacle antar pemain atau jatuhnya badan pada tanah tidak benar (tangan menopang/menahan beban berat badan yang berlebihan). 
9) Leher, Mulut, Hidung, dan Kepala

Cedera ini dapat terjadi, misalnya disebabkan oleh kesalahan pada saat melakukan beading, bodycontac antar pemain atau benturan dengan objek lain (gawang) atau jatuhnya badan pada tanah tidak benar.

10) Qrgan Dalam (kasus misalnya Alat Kemaluan atau Usus)

Cedera ini dapat terjadi karena adanya bodycontac / sleeding-tacle yang sangat keras di antara pemain.

a) Dislokasi (Pergeseran Tulang)

Dislokasi atau pergeseran tulang adalah suatu keadaan persendian tidak dalam keadaan anatomis (bergeser), dalam hal ini karena terjadi robekan yang mengakibatkan pergeseran tulang dari tempatnya. Gejala dislokasi antara lain dapat dilihat dengan ciri-ciri sebagai berikut: pembengkakan terjadi dengan cepat, terasa nyeri yang sedang sampai berat, terdapat perbedaan yang jelas pada bagian tubuh yang terluka. Pada pemain sepak bola dislokasi sering terjadi pada organ pergelangan kaki, jari-jari tangan, siku, lutut, bahu, atau punggung.

b) Patah Tulang (Fraktur)

Menurut pendapat Hartono S, (1993: 200) patah tulang (fraktur) adalah suatu keadaan tulang yang mengalami keretakan, pecah, atau patah. Menurut pendapat Hartono S, (1993: 201-202) patah tulang dibagi menjadi dua macam, yaitu: fraktur sederhana (simple fracture) dan fraktur kompleks (compound fracture).

Menurut pendapat Bernard B, (1978: 3) patah tulang adalah diskontinuitas dari jaringan tulang (patah tulang) yang biasanya disebabkan oleh adanya kekerasan yang timbul secara mendadak. Menurut Bernard B, (1978: 4-5) berdasarkan hubungan antara ujung tulang yang mengalami fraktur dengan jaringan-jaringan di sekitarnya, patah tulang dibedakan menjadi tiga macam, yaitu:

- Fraktur tertutup (fraktur simpleks) yaitu patahan tulang tidak mempunyai hubungan dengan udara terbuka.

- Fraktur terbuka (compound fracture) yaitu patahan tulang kulit terobek dari dalam frakmen tulang menembus kulit yang diakibatkan kekerasan dari luar.

- Fraktur komplikata yaitu patah tulang, persendian, syaraf, pembuluh darah atau organ viscera juga ikut terkena, fraktur ini bisa berbentuk fraktur terbuka dan tetutup. 
c) Suduken (Stitches)

Menurut pendapat yang dikemukakan oleh Gabe M dan Marshall $\mathrm{H}$, (1984: 117) suduken adalah sakit pinggang, rasa sakit yang menusuk dan tiba-tiba yang terasa di bagian atas perut yang merupakan suatu bentuk kejang otot. Suduken terjadi karena terhentinya suplai darah ke sekat rongga badan oleh tekanan dari paru-paru yang ada di atasnya dan paru-paru yang di bawahnya, banyaknya gas yang menggelembung di dalam usus besar sebagai akibat dari pencernaan makanan yang terlalu dekat dengan aktivitas olahraga, atau intoleransi terhadap susu dan terigu.

d) Kram Otot

Menurut pendapat yang dikemukakan oleh Gabe M dan Marshall H, (1984: 115-117) kram otot adalah kontraksi secara terus menerus yang dialami oleh otot atau sekelompok otot dan mengakibatkan rasa nyeri. Kram otot biasanya terjadi karena seseorang mengalami kelelahan yang berlebihan (overtraining), kekurangan garam dan mineral, kurang pemanasan atau penguluran, atau gangguan (terhambatnya) sirkulasi darah yang menuju ke otot-otot. Pada pemain sepak bola kram otot bisa terjadi pada: otot perut, otot paha, betis, jari tangan, atau jari kaki.

e) Pendarahan

Menurut pendapat Sarwoto dan Siti Aminah, (1982: 86-88) pendarahan terjadi karena pecahnya pembuluh darah sebagai akibat dari terjadinya trauma pukulan, tendangan, atau terjatuh. Pendarahan ini ada dua macam, yaitu penyadarahan dalam (darah berada di dalam rongga badan) dan pendarahan luar (darah keluar dari kulit).

f) Kejang (Shock)

Menurut pendapat Sarwoto dan Siti Aminah, (1982: 74) kejang (shock) adalah suatu keadaan yang timbul karena disebabkan gangguan pada otak, karena suplai darah ke otak berkurang, gangguan pernapasan, gangguan pencernaan (terlalu kenyang, terlalu lapar, atau kehausan).

g) Pingsan (Collaps)

Menurut pendapat Sarwoto dan Siti Aminah, (1982: 75) pingsan (collaps) adalah keadaan di mana seseorang mengalami kehilangan kesadaran yang bersifat sementara dan singkat. Pingsan biasanya disebabkan oleh berkurangnya aliran darah atau oksigen $\left(\mathrm{O}_{2}\right)$ dan glukosa dalam tubuh menuju ke otak, kepanasan, atau keracunan. 


\section{Macam-Macam Cedera pada Olahraga Sepakbola}

Berdasarkan letak terjadinya, cedera yang dapat dialami oleh atlet atau pemain sepak bola saat latihan atau bertanding antara lain dapat dibagi menjadi empat bagian:
a. Cedera di bagian kepala
b. Cederầ di bagian badan
c. Cedera di bagian lengan tangan
d. Cedera di bagian tungkai kaki.

\section{Pencegahan Terjadinya Cedera}

a. Pencegahan Melalui Lingkungan

Sebelum berolahraga (berlatih atau bertanding), seorang pemain atau pelatih harus mempersiapkan lapangan dan sarananya, baik kelayakannya, situasi dan kondisi lapangan, cuaca, dan kebersihan lapangan, sehingga aktivitas dapat dilakukan dengan aman dan nyaman.

b. Pencegahan melalui Perlengkapan yang Dipakai (Equipment)

Pemilihan dan penggunaan pakaian, sepatu atau perlengkapan lainya harus disesuaikan dengan kondisi lapangan atau cuaca. Pakaian harus bisa menyerap panas dan keringat, sedangkan pemilihan jenis sepatu yang baik disesuaikan dengan kondisi tanah atau lapangan.

c. Pencegahan melalui Latihan

Latihan merupakan proses untuk meningkatkan dan menyempurnakan keterampilan dan otomatisasi gerakan, sehingga tubuh akan adaptif, fisik, kekuatan, dan daya tahan tubuh meningkat. Dengan meningkatnya adaptasi tubuh tersebut kemungkinan terjadinya cedera dapat dicegah atau diminimalisasi.

d. Pencegahan melalui Pemanasan, Penguluran, dan Pendinginan

Pemanasan, penguluran, dan pendinginan (sebelum dan sesudah latihan) memberikan banyak manfaat, seperti menyiapkan organ tubuh, mempersingkat waktu istirahat (recovery), mengurangi ketegangan otot dan stress/tekanan jiwa. Pemanasan-penguluran dan pendinginan yang baik diharapkan dapat mencegah atau mengurangi terjadinya cedera

e. Pencegahan melalui Keterampilan

Penguasaan tingkat keterampilan, teknik maupun taktik baik secara individu maupun kerja sama tim yang dilakukan dengan baik dan benar diharapkan dapat mencegah atau mengurangi terjadinya cedera.

f. Pencegahan melalui Pola dan Pemilihan Makanan

Makanan dan minuman yang baik, menyehatkan dan dapat segera diserap oleh tubuh sebagai sumber tenaga dan pengganti ion/cairan tubuh dapat men- 
cegah dan mengurangi terjadinya cedera.

g. Pencegahan melalui Pelatih atau Maseur

Seorang pelatih pada saat menyusun atau melaksanakan program (beban) latihan perlu mempertimbangkan kondisi atlet agar atletnya tidak overload atau overtraining, sehingga cedera dapat dicegah atau diminimalisasi. Apabila seorang atlet mengalami ketegangan otot dan kelelahan akibat latihan, perlu dilakukan relaksasi atau pemijatan oleh pemijat (maseur) agar kondisi ototnya menjadi pulih kembali.

h. Pencegahan melalui Alat Bantu atau Pertolongan

Seorang atlet yang pernah mengalami cedera atau dalam masa penyembuhan perlu menggunakan alat bantu pengaman (deker, tensocrab, pembalut, dll) agar tidak terjadi cedera yang lebih parah lagi. Selain itu, pada saat latihan atau bertanding perlu adanya seorang pemijat (maseur) atau dokter yang apabila terjadi sesuatu yang tidak diharapkan dapat segera melakukan pertolongan (PPPK).

\section{KESIMPULAN}

Cedera dalam dunia olahraga yaitu rusaknya jaringan (lunak atau keras) baik otot, tulang atau persendian yang disebabkan oleh kesalahan teknis, benturan, atau aktivitas yang melebihi batas beban latihan (overtraining) yang dapat menimbulkan rasa sakit atau nyeri dan atau akibat dari kelebihan latihan dalam memberikan pembebanan yang terlalu berat (overload), sehingga otot, tulang atau persendian tidak lagi dalam keadaan atau posisi anatomis (dislokasi). Pencegahan cedera pada saat berlatih maupun pada saat bertanding dalam olahraga permainan sepak bola dapat dilakukan oleh seorang pemain atau atlet sepak bola dengan berbagai cara. Cara-cara pencegahan cedera dalam olahraga permainan sepak bola, antara lain: dengan penguasaan pengetahuan, sikap, dan perilaku yang baik.

Pengetahuan, sikap, perilaku untuk dapat mencegah terjadinya cedera tersebut dapat diwujudkan dengan cara pencegahan melalui: (1) lingkungan, (2) perlengkapan yang dipakai (equipment), (3) latihan, (4) pemanasan, penguluran, dan pendinginan yang baik, (4) keterampilan, (5) pemilihan dan pola makan yang baik, (6) patuh pada peraturan yang berlaku (bermain dengan sportif dan fairplay), (7) pelatih atau maseur, (8) alat bantu atau pertolongan, dan (9) perawatan dokter atau tim medis.

\section{DAFTAR PUSTAKA}

Gabe Mirkin dan Marshall Hoffman. (1984). Kesehatan Olabraga. Jakarta: PT. Grafidian Jaya.

G. La. Cava. (1995). Pengobatan Cedera Olabraga. (terjemahan oleh Hartono Satmoko).
Semarang: Dahara Prise. 
Giam, C.K. dan Teh. K.C. (1992). Ilmu Kedokteran Olabraga. (terjemahan oleh Hartono Satmoko). Jakarta: Bianarupa Aksara.

Hadianto Wibowo. (1995). Pencegahan dan Penatalaksanaan Cedera Olabraga. Jakarta: Penerbit Buku Kedokteran.

Muchtamaji. M. Ali. (2004). Pendidikan Keselamatan (Konsep dan Penerapan). Jakarta: Depora

M. Furqon H. (2002). Pembinaan Olahraga Usia Dini. Surakarta: Pusat Penelitian dan Pengembangan Keolahragaan (Puslitbang-OR) Universitas Sebelas Maret, Surakarta.

Paul dan Diare. (1993). Pencegahan dan Perawatan Cedera dalam Olabraga. (terjemahan oleh Hartono Satmoko). Jakarta: Bulan Bintang.

Saparjo Pribadi. (2010). Cedera Pemain Sepak Bola Peserta Piala Dunia Afrika Selatan. (www.rakyatmerdeka.co.id), diunduh 11 Januari 2010.

Sarwoto dan Siti Aminah. (1982). Dasar-dasar Pendidikan Kesehatan. Surakarta: FIPUniversitas Sebelas Maret.

Sukintaka. (2000). Administrasi Pendidikan Jasmani. Yogyakarta: Fakultas Ilmu Keolahragaan UNY.

(1982). Permainan Sepakbola (Teori dan Praktek) Yogyakarta: IKIP Yogyakarta.

Syamsuri E. (1984). Cedera dalam Olabraga. Jakarta: PT Intan Pariwara.

Tudor O., Bompa. (1994). Theory and Methodology of Training (third edition). Departement of Physical Education, New York University, Toronto, Ontario Canada: Kendall/Hunt Publishing Company.

Wade, Allen. (1978). The FA Guide to Teaching Football (first published). London: Hainemann. 